\title{
A WIDE BAND MICROSTRIP MONOPOLE SLOT ANTENNA FOR CHIPLESS RFID APPLICATIONS
}

\author{
Chaker ESSID ${ }^{1}$, Hedi SAKLI ${ }^{2,3}$ and Nizar SAKLI ${ }^{3}$ \\ ${ }^{1}$ Tunisia Polytechnic School, Carthage University, SERCOM \\ Research Laboratory, Tunisia \\ ${ }^{2}$ National Engineering School of Gabes, MACS Research Laboratory, \\ University of Gabes, Gabes, 6029, Tunisia \\ ${ }^{3}$ EITA Consulting, 5 Rue du Chant des Oiseaux, 78360 Montesson, France
}

\begin{abstract}
A new design of wideband microstrip antenna, where slots are placed on structure, is proposed. Also, a newly structure of a monopole antenna based on the noches form is designed using the HFSS. It has been found that the characteristics of new microstrip antenna are comparable to the conventional patch antennas, whereas its gain, directivity, and radiating efficiency are remarkably improved which make it to be useful in RFID chipless applications. The proposed antenna operates from 11.45 to $13.28 \mathrm{GHz}$, and 14.61 to $19.55 \mathrm{GHz}$ can be used in RFID chipless applications, and it has a bandwidth about $677 \mathrm{MHz}$. The return loss of the proposed antenna is indeed below -10 dB. Prototype for all antennas are fabricated and measured and a good agreement between the measured and simulated results is achieved.
\end{abstract}

\section{KEYWORDS}

Slot antenna, notches, monopole antenna, chipless RFID, multi resonant, wide band

\section{INTRODUCTION}

Wireless communications are of great importance in the telecommunications sector. And in these applications where the size, weight, cost, performance, ease of installation and aerodynamic profile are constraining, profiled antennas such as microstrip are required. However, the microstrip antennas generally have narrow bandwidths and, in general, are half-wavelength structures operating at the fundamental resonance mode [1], the various research works are striving to solve the problem of the narrow bandwidth, and various structures have been studied to extend the bandwidth [2], for example, by introducing slots in a microstrip patch configuration. Also, compared with ordinary microstrip patch antenna, the printed monopole antenna has become a suitable choice due its wider bandwidth, lower radiation loss and lower dispersion [3]. They are also more likely to join various additional structures by etching slots on the radiating area, with the resulting multiband characteristic. For all that, monopole broadband antenna accompanied with slots is often used kind of structure hooked for multi resonant antenna, not only for its miniaturization of the antenna dimension effectively but also for the ability of generation of multiband characteristic. 
The reason for this is that some microstrip monopole antennas are required in some applications, but not others, i.e., some applications require wide bandwidth, short-range and low-cost tags. Hence, the design and choice of RFID systems are application specific.

Moreover, RFID identification technology has grown considerably in recent decades and it can be applied in many applications such as industrial robotics, wireless gas sensors, wireless humidity sensors [4]. In the RFID literature is classified into several categories low frequency (LF), high frequency (HF), ultrahigh frequency (UHF), superhigh frequency (SHF), and ultrawide band frequency(UWBF) RFID systems[5][6].Recently, the price of silicon chips has gone down exponentially causing in a significant reduction in cost of the chip based RFID tags. However, the chip based RFID tags are not yet economical enough to completely replace the barcodes for item level tagging [5]. Chipless RFID tags can be a more suitable choice for item level tagging. The chipless RFID tags are also expected to possess higher read range as no RF power from the reader signal is exploited to power up the chip [8]. Multi-resonator structures are employed to encode the data in frequency signature technique which is one of the main data encoding technique of the core's chipless RFID [9].

In this paper, the prospects of improving the bandwidth and the data capacity per unit area further are discussed by placing notches and slots on the radiating element.

\section{AnTEnNa Design}

The wide band monopole slot antenna is based on a squared microstrip patch filled with notches and sub slots structures in figure 1 and 2 respectively. These slots structures behave as miniaturization method, allowing the widening of the bandwidth.

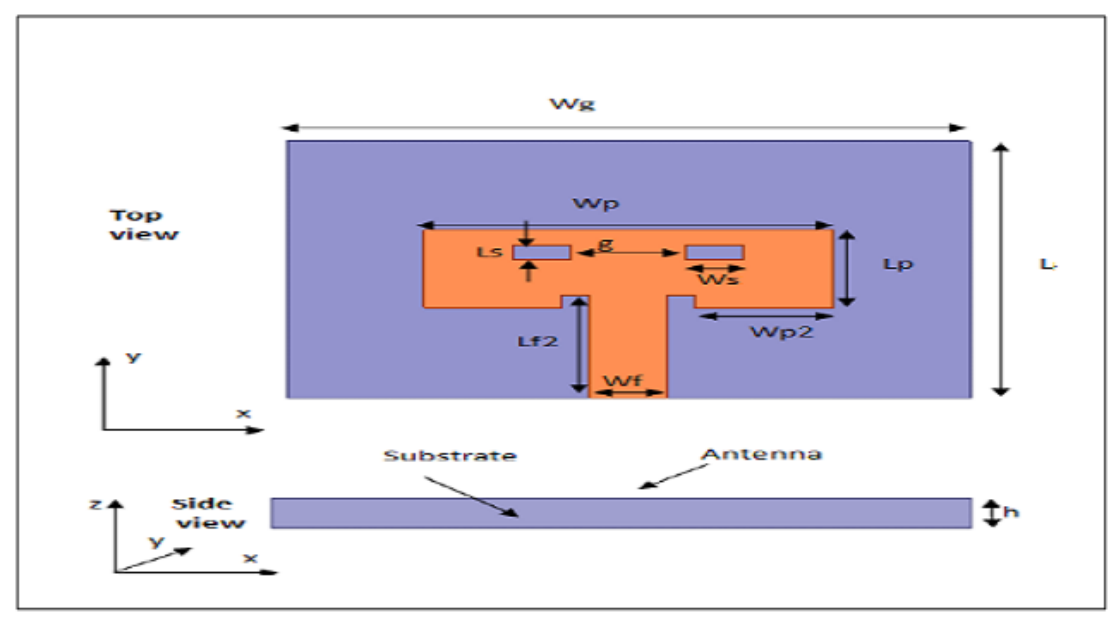

Figure.1. The layout of the proposed monopole wideband antenna: top view 


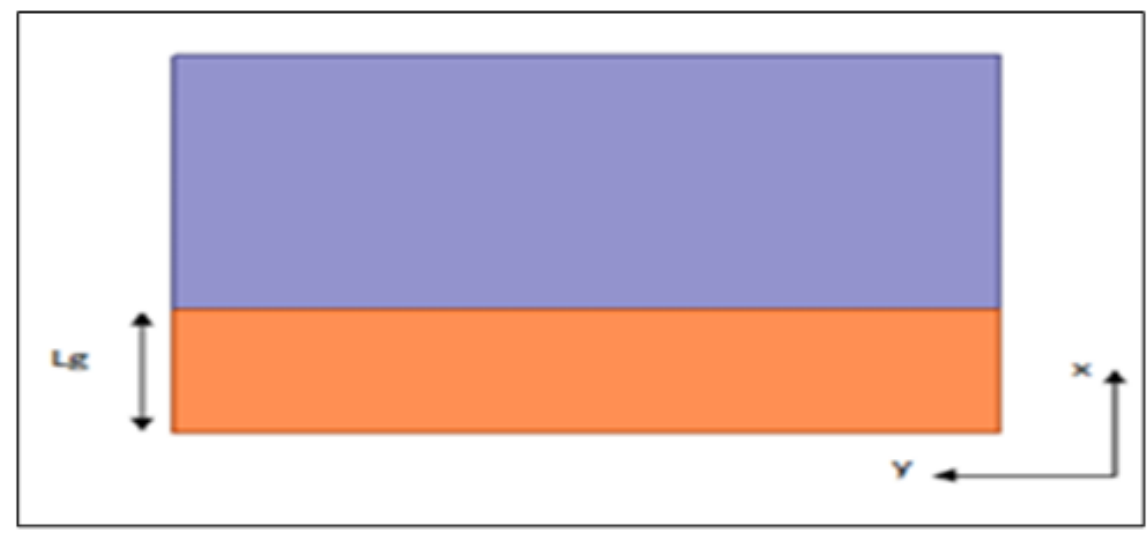

Figure.2. The layout of the proposed monopole wideband antenna: bottom view.

The antenna structure presented in this study can be studied in three different states that have been shown in this part. As shown in figure 3, this antenna is initially provided by rectangular radiation patch with a width of $25 \mathrm{~mm}$ and a length of $20 \mathrm{~mm}$ printed on a FR4-epoxy substrate with $\mathrm{h}=1.6 \mathrm{~mm}$ and $\varepsilon=4.4$. the patch is fed by a coplanar line with $50 \Omega$ input impedance. The dimensions of the line are $7.8 * 2.86 \mathrm{~mm}^{2}$. the port feeding line is places at the middle of the edge of the patch. This first design will work only on $5.8 \mathrm{GHz}$ and $11.8 \mathrm{GHz}$ frequency band reffering to figure 6 .

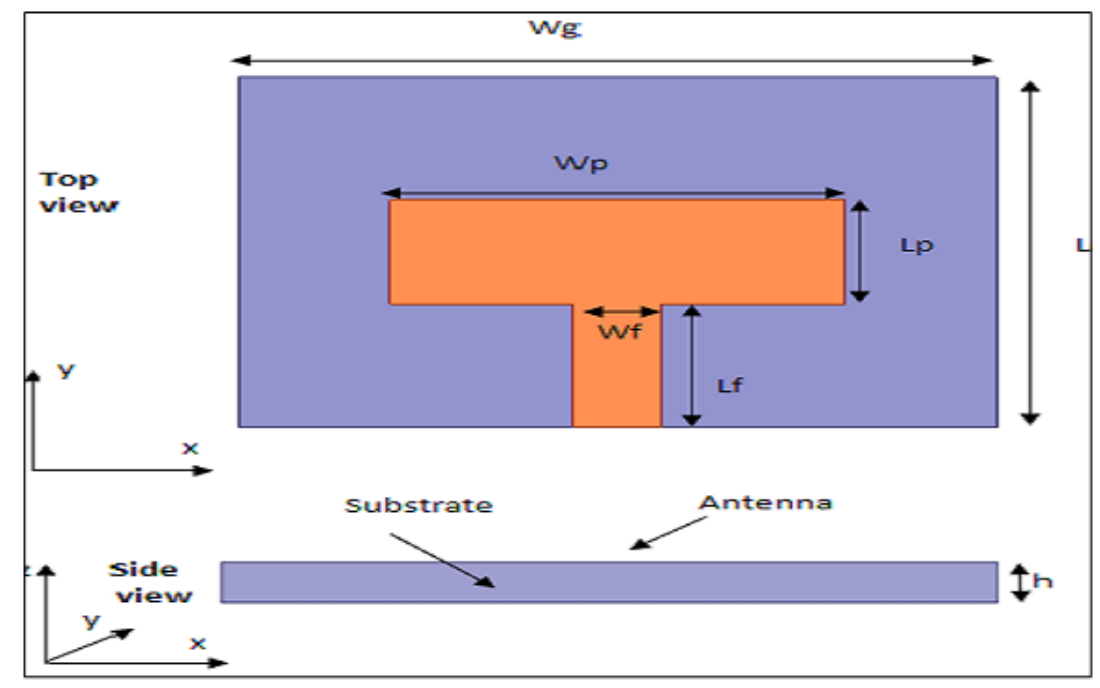

Figure.3. the design of the conventional antenna structure

By adding two rectangular slots to radiation patch, antenna will cover three frequencies of 5.8, 13 and $17 \mathrm{GHz}$ resonant frequency. The design step is shown in fig 4. The dimensions of the rectangular slots are $1.88 * 1 \mathrm{~mm}^{2}$ spaced $3.75 \mathrm{~mm}$. 


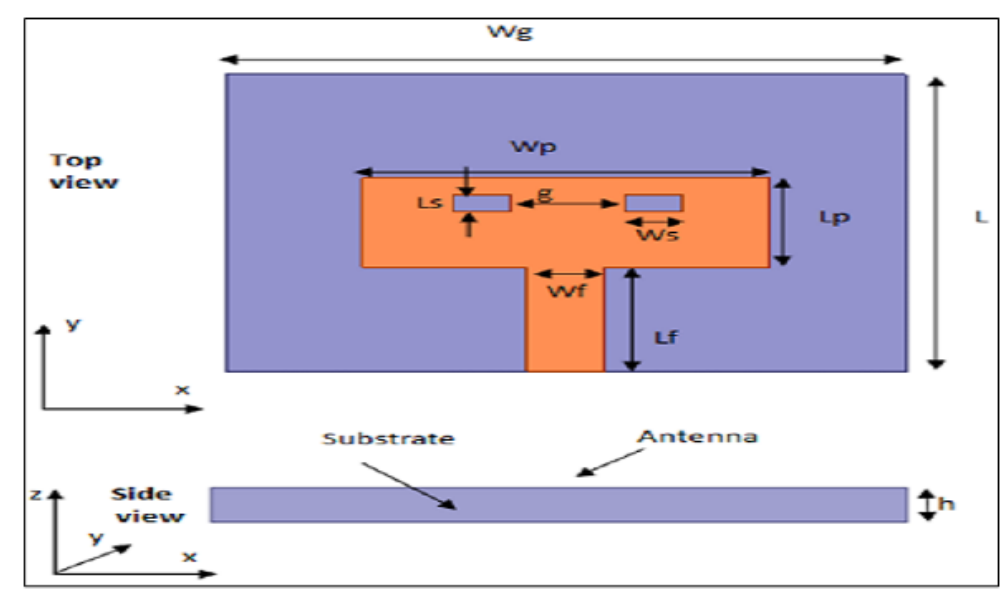

Figure.4. The design of the "antenna +2 slots" structure

The antenna parameter values are shown in table 1. Antenna three shown in fig 1 and it is the last stage of design process that the final structure of antenna will be obtained by creating two notches on the radiation patch. In this design 5.8, 12 and $16 \mathrm{GHz}$ resonant frequency are obtained.

Table1. Antenna parameters.

\begin{tabular}{|l|l|l|l|}
\hline $\mathrm{L}_{\mathrm{f}}(\mathrm{mm})$ & 7.8 & $\mathrm{G}(\mathrm{mm})$ & 0.5 \\
\hline $\mathrm{L}_{\mathrm{f} 2}(\mathrm{~mm})$ & 7.8 & $\mathrm{~L}_{\mathrm{s}}(\mathrm{mm})$ & 3.75 \\
\hline $\mathrm{W}_{\mathrm{f}}(\mathrm{mm})$ & 2.86 & $\mathrm{~W}_{\mathrm{s} 2}(\mathrm{~mm})$ & 1 \\
\hline $\mathrm{L}_{(\mathrm{mm})}$ & 20 & $\mathrm{~L}_{\mathrm{g}}(\mathrm{mm})$ & 6.5 \\
\hline $\mathrm{W}_{\mathrm{g}}(\mathrm{mm})$ & 25 & $\mathrm{~W}_{\mathrm{p}}(\mathrm{mm})$ & 15 \\
\hline $\mathrm{L}_{\mathrm{p}}(\mathrm{mm})$ & 6 & $\mathrm{~W}_{\mathrm{p} 2}(\mathrm{~mm})$ & 5.07 \\
\hline
\end{tabular}

\section{EXPERIMENTAL RESULTS}

Prototypes of these antennas have been manufactured in figure 5. The experimental S parameters of these antennas are also plotted in figure 6. It can be seen that simulations and measurements agree.

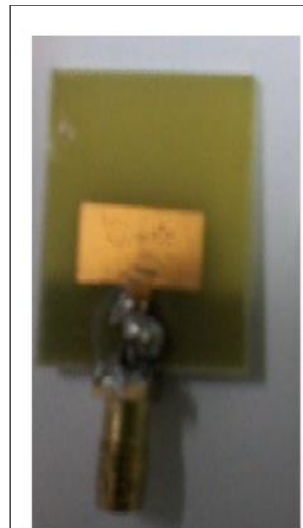

(a)

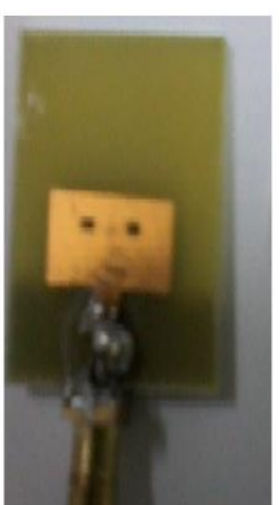

(b)

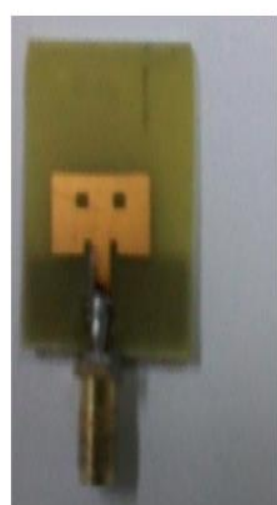

(c)

Figure5. Fabricated prototype of the proposed antennas, (a) monopole antenna, (b) "antenna + 2 sub slots", (c) "notch antenna + 2 sub slots" 
Figure 6 shows the simulated and measured insertion loss versus frequency of the multi resonating antenna. From this, we can see five distinct resonant nulls due to the slots and notches forms. Each notch and slot can be used to a particular resonance which can be used for data en coding.

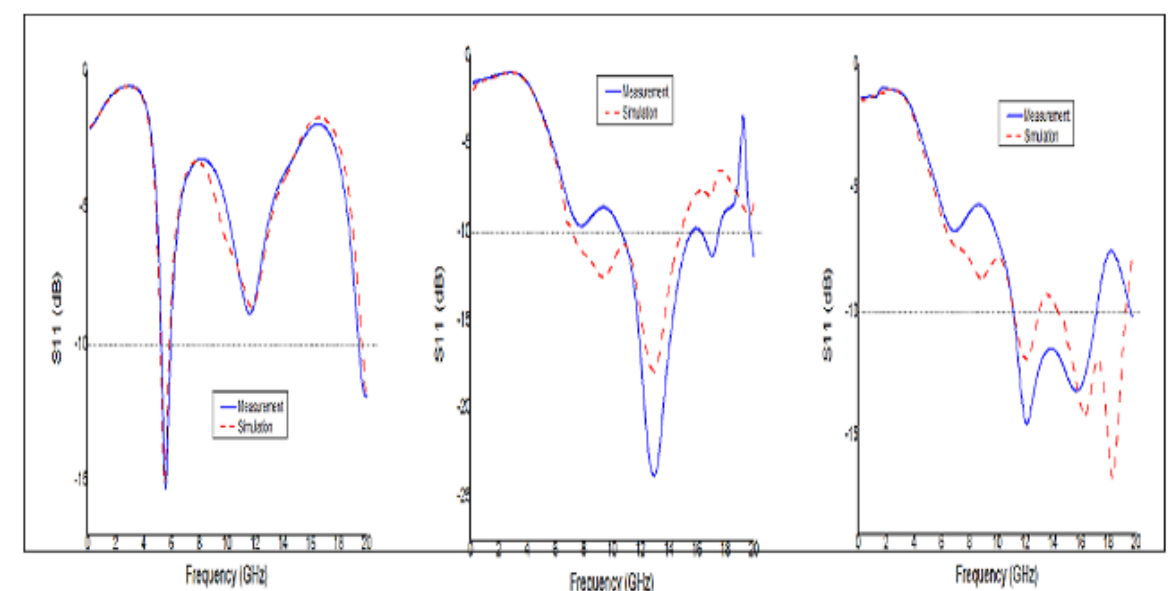

(a)

(b)

(c)

Figure 6. Measured and simulated reflection coefficients of the proposed antennas, (a) monopole antenna, (b) "antenna + 2 sub slots", (c) "notch antenna + 2 sub slots"

The second prototype covers a frequency band ranging from 7.27 to $14.85 \mathrm{GHz}$, while the measured antenna covers a frequency band from 10.2 to $14.8 \mathrm{GHz}$. The last antenna has two frequency bands: the first is ranging from 11.79 to $13.46 \mathrm{GHz}$, while, the second is situated between 15.15 to $15.49 \mathrm{GHz}$ and has a bandwidth of $677 \mathrm{MHz}$. It is noted that the measured antenna covers a frequency band from 11.79 to $15.2 \mathrm{GHz}$.

Simulation results prove 5 equally spaces resonant notched are observed in the 4 to 20GH frequency band. Each notch encodes a unique data bit.

Figure. 7 and figure. 8 show the gain of each antenna in $\mathrm{E}$ and $\mathrm{H}$ planes.

First, figure.7 (a) and figure. 8 (a) shows the radiation patterns of monopole antenna at $7 \mathrm{GHz}$ in the E-plane. The measurements seem accurate more than those of simulation ones.

Second, figure.7 (b) and figure. 8 (b) present the radiation pattern of "antenna +2 sub slots" at 8.4 $\mathrm{GHz}$, the results are the same. In addition, figure. 7 (c) and figure. 8 (c) present the radiation patterns of "antenna notched +2 sub slots" at $12 \mathrm{GHz}$; measurement and simulation results are the same behavior. 


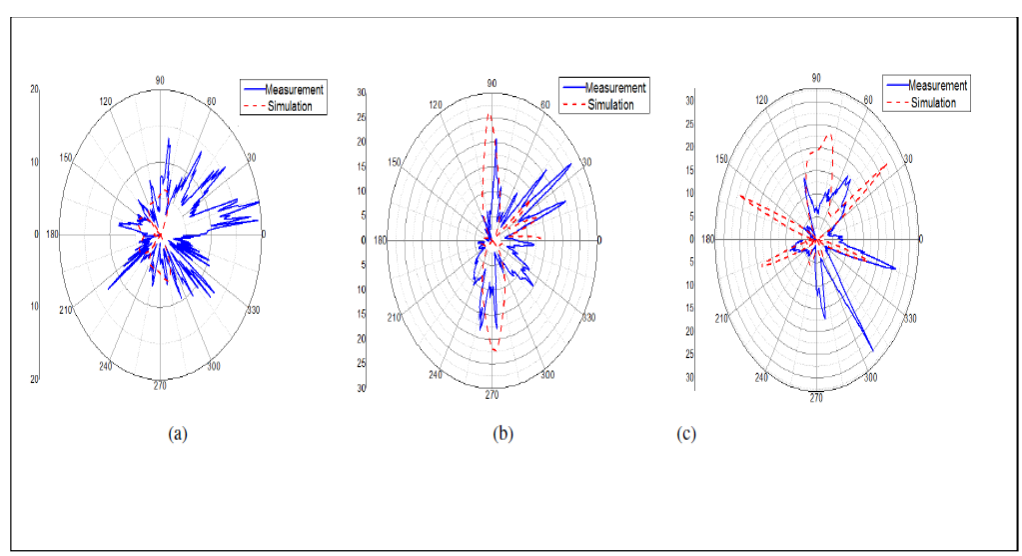

Figure.7. Measured and simulated far field normalized radiation patterns of the proposed antenna in E plane,(a) monopole antenna at $7 \mathrm{GHz}$,

(b) "antenna +2 sub slots" at $8.4 \mathrm{GHz}$, (c) "notch antenna +2 sub slots" at $12 \mathrm{GHz}$

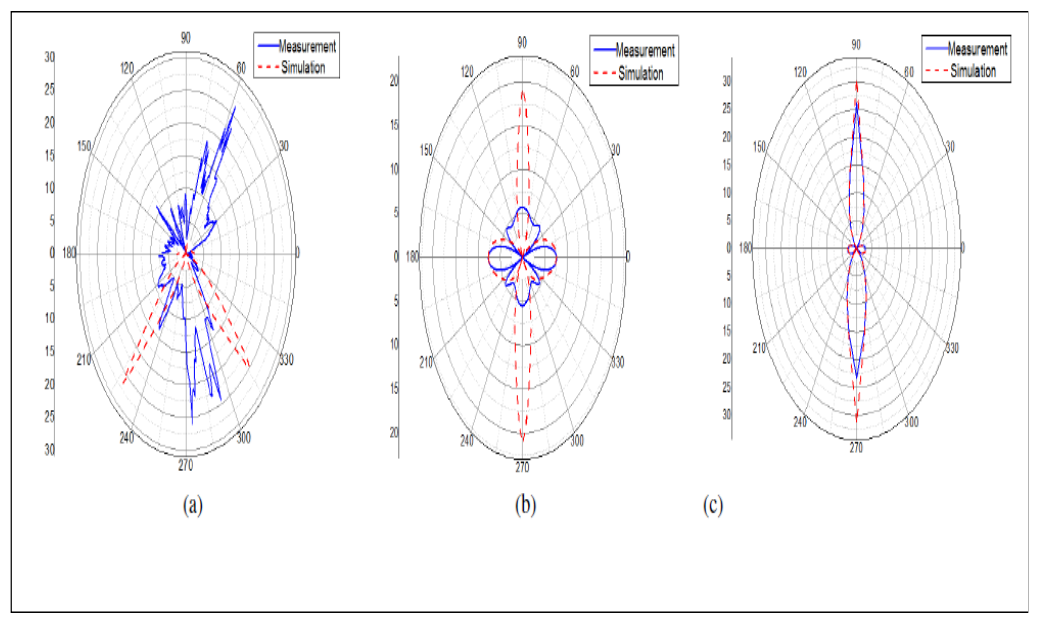

Figure.8. Measured and simulated far field normalized radiation patterns of the proposed antenna in $\mathrm{H}$ plane,(a) monopole antenna at $7 \mathrm{GHz}$,

(b) "antenna +2 sub slots" at $8.4 \mathrm{GHz}$, (c) "notch antenna +2 sub slots" at $12 \mathrm{GHz}$

However, comparing our proposed monopole antenna with conventional patch antenna, it is noted that the conventional patch antenna uses microstrip technology, but this prototype is structured based on the monopole design which is advantageous as regards the microstrip technology. Indeed, this technology presents the advantage of a compactness (reduced volume), cost-effective production and simplicity of components implement.

Thus, taking an example from the literature reported in [7] can be used to display this comparison. In their work, the authors present a patch antenna disposed on FR4 epoxy substrate with a thickness of $1.6 \mathrm{~mm}$ and a permittivity $\varepsilon=4.4$. The overall size of the antenna is $50 * 40$ $\mathrm{mm}^{2}$, the width and the length of the patch are $24 \mathrm{~mm}$ and $22 \mathrm{~mm}$ respectively. This antenna is fed by a microstrip line with a width and a length of $2.75 \mathrm{~mm}$ and $15 \mathrm{~mm}$ respectively. Thus, this patch antenna covers the frequency 6.5 GHz. Moreover, most conventional patch antenna possesses oversized dimensions particularly when the application referred is low frequency and it seems covering a single frequency band which is so narrow. In our case, the proposed antenna has a relatively small size, a wide frequency band, a best gain and is more directives compared to that of the conventional patch antenna. 


\section{Conclusions}

In this paper, a novel chipless RFID antenna is presented, which can be configured as monopole wide band antennas. Proposed approach offers enhanced data capacity. A 5-bit chipless RFID antenna is also presented. High gain and wide bandwidth were found to be $4.78 \mathrm{~dB}$ and $677 \mathrm{MHz}$ respectively and will be used to prolong the read range.

\section{REFERENCES}

[1] Tayeb A. Denidni Qinjiang Rao,"Ultra-wideband slot antenna for wireless communication system", International Journal of RF and Microwave Computer Aided Engineering, Volume 16, Issue 4.

[2] Kang Ding ,Cheng Gao,Tong bin Yu, De xin Qu, "CPW fed C-shaped slot antenna for broadband circularly polarized radiation", International Journal of $R F$ and Microwave Computer-Aided Engineering Volume 25, Issue 9.

[3] Broggi Max Ammann and Zhi Ning Chen., (2003) "A wide-band shorted planar monopole with bevel”. ,IEEE Trans. Antenna.

[4] Adbulkawi, W. M., \&Sheta, A. F. A. (2018, April), "Printable Chipless RFID Tags for IoT Applications", 1st International Conference on Computer Applications \& Information Security (ICCAIS) IEEE (pp. 1-4).

[5] A. Vena, E. Perret, and S. Tedjini, (Dec. 2011), "Chipless RFID tag using hybridcoding technique," IEEE Trans. Microw. Theory Techn., vol. 59, no. 12,pp. 3356-3364.

[6] M. M. R. Rezaiesarlak. (2015), "Chipless RFID Design Procedure and Detection Techniques"

[7] JA Evans and MJ Ammann. (2006), "Reduced-size reconfigurable tri-band printed antenna with cpw tapered-feed and shorting post", Microwave and optical technology letters, 48(9):1850-1853.

[8] Abdelnasser A Eldek, Atef Z Elsherbeni, Charles E Smith, and K-F Lee.(2002), "Wideband rectangular slot antenna for personal wireless communication systems", Antennas and Propagation Magazine, IEEE, 44(5):146-155.

[9] Wonseob Kim, Seokjin Hong, Hoon Park, and Jaehoon Choi. (2007), "Planar monopole antenna with wide impedance bandwidth for mobile handset application", Microwave and optical technology letters, 49(4):779-781.

(C) 2020 By AIRCC Publishing Corporation. This article is published under the Creative Commons Attribution (CC BY) license 